\title{
PENGEMBANGAN LKPD BERBASIS SWISHMAX MATERI PERISTIWA MENGISI KEMERDEKAAN DENGAN PENGUATAN KARAKTER TANGGUNG JAWAB DI KELAS V
}

\author{
Fajar Habib Krismon', Zainuddin ${ }^{2}$, Arda Purnama Putra ${ }^{3}$ \\ 1,2,3 Fakultas Ilmu Pendidikan, Universitas Negeri Malang, Jl. Semarang 5 Malang, 65145, Indonesia \\ fajar.habib.1601516@students.um.ac.id ${ }^{1}$, mohammad.zainuddin.fip@um.ac.id ${ }^{2}$, \\ arda.purnama.fip@um.ac.id ${ }^{3}$
}

\begin{abstract}
The study aims to produce a Swishmax -based Student's Activity Sheets on event material fill independence with a character reinforcement worthy responsibility used as material teaching of ips content of event material fills independence. This research and development uses the model Dick and Carey. Product feasibility testing is performed by material experts, media experts, and users. Then the field trials were carried out to students at SDN Mojoagung V. Based on validation and material, media and user tests. Material validation reaches a rate of $100 \%$ of validity and a media validation of $91 \%$. In terms of practicality reach $100 \%$ of the users are teachers of class $\mathrm{V}$ and $100 \%$ of students.
\end{abstract}

Keywords: student's activity sheets, independence fill event material, swishmax

\begin{abstract}
Abstrak: Penelitian ini bertujuan untuk menghasilkan LKPD berbasis Swishmax pada materi peristiwa mengisi kemerdekaan dengan penguatan karakter tanggung jawab yang layak digunakan sebagai bahan ajar muatan ips materi peristiwa mengisi kemerdekaan. Penelitian dan pengembangan ini menggunakan model Dick and Carey. Pengujian kelayakan produk dilakukan oleh ahli materi, ahli media, dan pengguna. Kemudian uji coba lapangan dilakukan kepada siswa kelas V SDN Mojoagung. Berdasarkan uji kevalidan materi, media, dan pengguna. Validasi materi mencapai tingkat kevalidan $100 \%$ dan validasi media $91 \%$. Sedangkan dari segi kepraktisan mencapai $100 \%$ dari pengguna yaitu guru kelas $\mathrm{V}$ dan $100 \%$ dari siswa.
\end{abstract}

Kata kunci: LKPD, materi peristiwa mengisi kemerdekaan, swishmax

Ilmu Pengetahuan Sosial merupakan muatan yang bersumber dari kehidupan sosial masyarakat yang diseleksi dengan menggunakan konsep-konsep ilmu sosial yang digunakan untuk kepentingan pembelajaran. Kehidupan sosial masyarakat senantiasa mengalami perubahanperubahan dari waktu ke waktu. Perubahan tersebut dapat dilihat baik dalam konteks keruangan (tempat tinggal) maupun konteks waktu. Berbagai perubahan yang terjadi dalam kehidupan masyarakat harus dapat ditangkap oleh lembaga pendidikan yang kemudian menjadi sumber materi pembelajaran. Sumber bahan pelajaran secara formal dapat dituangkan dalam bentuk kurikulum (Kemdikbud, 2007). Salah satu materi yang berkaitan dengan kehidupan sosial masyarakat adalah 
peristiwa mengisi kemerdekaan. Materi peristiwa mengisi kemerdekaan meliputi dua pokok bahsan yaitu: peristiwa lahirnya pancasila dan peran pancasila dalam keragaman bangsa.

Dalam kitab Sutasoma, pancasila berarti berbatu sendi yang lima atau pelaksanaan kesusilaan yang lima. Lahirnya Pancasila sebagai dasar negara terjadi pada saat Sidang BPUPKI (Badan Penyelidik Usaha Persiapan Kemerdekaan Indonesia) yang dilakukan beberapa usulan oleh tiga tokoh bangsa. Ketiga tokoh bangsa tersebut yaitu: Muhammad Yamin, Proft. Dr. Mr. Soepomo, dan Ir. Soekarno. Hingga pada tanggal 18 Agustus 1945, disahkan Undang-Undang Dasar 1945 pada Sidang Panitia Persiapan Kemerdekaan Indonesia (PPKI), termasuk Pembukaan Undang-Undang Dasar 1945. Di dalam Pembukaan Undang- Undang Dasar 1945, termuat isi rumusan Prinsip Dasar Negara yang disebut Pancasila, tepatnya pada alinea IV yang berbunyi sebagai berikut. (a) Ketuhanan Yang Maha Esa, (b) Kemanusiaan yang Adil dan Beradab, (c) Persatuan Indonesia, (d) Kerakyatan yang dipimpin oleh hikmat kebijaksanaan dalam permusyawaratan/perwakilan, (e) Keadilan sosial bagi seluruh rakyat Indonesia. Lahirnya pancasila sebagai dasar negara memiliki peranan yang penting dalam keragaman bangsa (Mahanani, Putra, \& Kristianingsih, 2018).

Pancasila sebagai dasar negara merupakan kepribadian dan pandangan hidup bangsa Indonesia. Maka, nilai-nilai luhur yang terkandung di dalamnya harus dipahami dan diamalkan oleh setiap warga negara Indonesia. Dapat kita ketahui bahwa masyarakat Indonesia yang terdiri atas berbagai suku bangsa yang hidup dalam lingkup budayanya masing-masing. Budaya yang beraneka ragam ini menunjukkan kekayaan budaya bangsa Indonesia. Sehingga Pancasila dalam keberagaman bangsa memiliki peran sebagai berikut. (a) dapat menentukan sikap dan perilaku dalam menghadapi perubahan-perubahan yang terjadi karena memiliki dasar yang kuat, (b) sebagai kepribadian dan pandangan hidup bangsa Indonesia, dan (c) sebagai tolak ukuran dan pedoman nilai dan norma untuk menerima atau menolak pengaruh globaslisasi dan perkembangan iptek. Dalam proses pembelajaran ips diperlukan media pembelajaran yang dikemas secara menarik agar proses pembelajaran tidak membosankan. Guru harus kreatif dalam menyajikan pembelajaran, memberikan layanan, dan kemudahan belajar kepada siswa. Untuk mengetahui proses pembelajaran yang dilakukan di SDN Mojoagung pelaksana peneliti melakukan kegiatan wawancara dengan guru kelas V.

Hasil wawancara yang dilakukan dengan guru di SDN Mojoagung pada tanggal 13 Desember 2019 di peroleh informasi terkait dengan proses pembelajaran yang sudah sampai tema 5. Kegiatan pembelajaran dilakukan menggunakan bahan ajar buku guru dan buku siswa dengan media penunjang berupa LKPD. LKPD yang digunakan masih dalam bentuk konvensional sehingga membuat peserta didik kurang tertarik ketika mengerjakan latihan soal. Selain itu tanggung jawab peserta didik dalam mengerjakan tugas dari guru masih rendah hal tersebut menyebabkan pemahaman peserta didik rendah. Salah satu muatan yang sulit di pahami oleh peserta didik yaitu IPS. Pernyataan tersebut dibuktikan dari hasil belajar peserta didik muatan IPS rendah. Hasil yang diperoleh peneliti menemukan bahwa model pembelajaran yang digunakan belum bervariatif dan kurang efektif. Dalam pembelajaran, guru hanya mengandalkan media pembelajaran yang sudah tersedia di sekolah.

Selain pentingnya peran guru dalam keberhasilan proses belajar peserta didik tetapi juga harus ditunjang dengan penanaman karakter siswa dalam suatu proses pembelajaran. Salah satu penanaman karakter yang harus dimiliki peserta didil yaitu tanggung jawab. Tanggung jawab memegang peranan penting dalam setiap aspek kehidupan manusia. Asmani (2009), menyatakan bahwa tanggung jawab adalah perasaan kuat yang disertai kebulatan tekad untuk melaksanakan tugas sebaik-baiknya. Seseorang akan bertindak seenaknya sendiri jika tidak memiliki tanggung 
jawab. Sebaliknya, jika memiliki tanggung jawab yang tinggi maka akan mendorong seseorang untuk menyelesaikan pekerjaan dengan baik.

Berdasarkan pemaparan masalah di atas, alternatif solusi yang dapat diberikan yaitu dengan mengimplementasikan pembelajaran yang variatif dan lebih inovatif salah satunya dengan menggunakan aplikasi Swishmax. Swishmax adalah salah satu program yang digunakan untuk membuat animasi taks, gambar, dan suara secara cepat dan mudah. Swishmax saat ini dilengkapi lebih dari 230 efek. Selain itu Swishmax juga memiliki tool untuk membuat garis, kotak, elips, kurva, motion path, sprite, tombol rollover, dan form input. Swishmax adalah software animasi flash yang dapat digunakan untuk keperluan pembuatan presentasi, animasi, website serta bisa dijadikan tambahan untuk pembuatan video editing. Swishmax ini memiliki keunggulan sebagai berikut sebagai berikut: Swishmax relatif lebih mudah digunakan dibandingkan dengan Macromedia Flash dan dengan hasil relative sama Swishmax sudah dilengkapi dengan berbagai animasi yang menarik dan mudah dalam penggunaanya. Swishmax juga mampu menangani link antar objek maupun dokumen. Swishmax memungkinkan melakukan Import file aminasi seperti animasi flash. Dapat dipadukan dengan beberapa aplikasi program lain seperti Photoshop, Corel Draw.

\section{METODE}

Model penelitian dan pengembangan yang ditempuh dalam melakukan pengembangan LKPD berbasis Swishmax dengan penguatan karakter tanggung jawab menggunakan model pengembangan Dick and Carey memiliki 10 tahapan (Tegeh, 2014) yaitu analisis kebutuhan, analisis pembelajaran, analisis pembelajaran dan konteks, menentukan tujuan pembelajaran, mengembangkan instrumen penelitian, mengembangkan strategi pembelajaran, mengembangkan dan memilih bahan pembelajaran, mendesain dan melakukan evaluasi formatif, revisi, dan mendesain dan melakukan evaluasi sumatif. Berdasarkan pada prosedur pengembangan pengembangan LKPD berbasis Swishmax dengan penguatan karakter tanggung jawab di kelas V SDN Mojoagung melalui langkahlangkah berikut.

Pada tahap analisis kebutuhan ini dilakukan dengan cara mengumpulkan data yang digunakan untuk kepentingan penelitian yaitu berupa permasalahan dan kebutuhan di SD. Analisis kebutuhan ini dilakukan melalui kegiatan wawancara yang telah dilakukan pada 13 Desember 2019 kepada Guru kelas V SDN Mojoagung. Wawancara dilakukan untuk mengetahui ketersediaan bahan ajar, media pembelajaran, dan kegiatan pembelajaran di kelas. Tahap ini bertujuan untuk mengkaji tujuan dari produk yang akan dikembangkan. Produk akan dianalisis sesuai dengan kurikulum yang berlaku untuk menentukan produk yang sesuai dengan tuntutan kurikulum. Analisis kurikulum akan menghasilkan materi yang disesuaikan dengan kompetensi inti dan kompetensi dasar.

Setelah identifikasi tujuan pembelajaran, langkah selanjutnya adalah menentukan langkah yang dilakukan agar tujuan pembelajaran dapat tercapai. Proses analisis pembelajaran pada akhirnya akan menentukan pengetahuan, keterampilan, dan sikap yang dibutuhkan oleh peserta didik.

Langkah selanjutnya adalah analisis paralel dari peserta didik, pihak yang akan belajar keterampilan hingga akhirnya menerapkan dalam kehidupannya. Keterampilan awal peserta didik, kecenderungan/prioritas, dan sikap ditentukan bersama dengan karakteristik pembelajaran agar menghasilkan produk yang sesuai dengan kebutuhan. Langkah selanjutnya adalah menuliskan pernyataan spesifik dari apa yang peserta didik dapat lakukan ketika merka menyelesaikan pembelajaran. Pernyataan ini berasal dari keterampilan yang diidentifikasi dalam analisis pembelajaran, mengidentifikasi keterampilan yang harus dipelajari kondisi dimana keterampilan akan didemonstrasikan, dan kriteria untuk tujuan pembelajaran yang berhasil. 
Berdasarkan tujuan yang telah ditentukan, langkah selanjutnya adalah mengembangkan penilaian dan mengukur kemampuan peserta didik untuk melakukan apa yang menjadi tujuan pembelajaran. Penekanan utama ditempatkan pada hal yang berkaitan dengan jenis keterampilan yang diuraikan dalam tujuan persyaratan penilaian. Langkah selanjutnya adalah mengidentifikasi strategi untuk digunakan dalam pembelajaran. Strategi pembelajaran digunakan untuk membantu perkembangan peserta didik di dalam kegiatan belajar, yang mencakup kegiatan sebelum pembelajaran (stimulasi), penyajian konten baru dengan contoh dan demonstrasi, kegiatan pembelajaran dan penilaian, dan tindak lanjut kegiatan yang berhubungan dengan kemampuan yang baru dipelajari.

Setelah mengembangkan strategi pembelajaran, langkah selanjutnya adalah menghasilkan bahan pembelajaran yang sesuai dengan strategi pembelajaran. Bahan pembelajaran biasanya terdiri dari panduan bagi peserta didik, materi pelajaran, dan penilaian. Langkah selanjutnya adalah melakukan evaluasi, evaluasi dilakukan untuk mengumpulkan data yang digunakan untuk mengidentifikasi masalah dalam pembelajaran dan membuat pembelajaran menjadi lebih baik lagi.

Setelah melakukan evaluasi, langkah selanjutnya adalah melakukan revisi produk. Data evaluasi formatif berguna untuk mengetahui kekurangan produk dan selanjutnya digunakan untuk memperbaiki kualitas produk. Langkah terakhir dalam pengembangan produk adalah melakukan evaluasi sumatif, yaitu evaluasi produk yang menghasilkan niali absolut atau relatif dan terjadi setelah produk dievaluasi secara formatif dan direvisi.

Jenis data pada penelitian ini berupa data kualitatif dan kuantitatif. Data kualitatif diperoleh dari catatan dan wawancara proses pembelajaran di SDN Mojoagung sebelum dan sesudah penerapan produk, sedangkan data kuantitatif diperoleh dari penyebaran angket dan observasi uji coba terbatas di kelas V SDN Mojoagung. Kedua data tersebut digabungkan untuk memperoleh kritik dan saran terhadap produk sehingga dapat dilakukan revisi produk dengan baik.

\section{HASIL}

Hasil penelitian dan pengembangan ini yaitu berupa LKPD berbasis Swishmax dengan penguatan karakter tanggung jawab materi peristiwa mengisi kemerdekaan pada kelas V SDN Mojoagung. Produk dibuat menarik dengan dilengkapi warna yang sesuai dengan materi. Materi yang terdapat pada LKPD ini juga mudah dipelajari karena dilengkapi dengan gambar ilustrasi, sehingga memudahkan siswa dalam memahami pembelajaran. Selain itu pada latihan soal disertai dengan skor yang hasil kerja siswa sehingga siswa langsung mengetahui nilai yang diperoleh seperti pada gambar1 dan gambar 2 berikut ini.

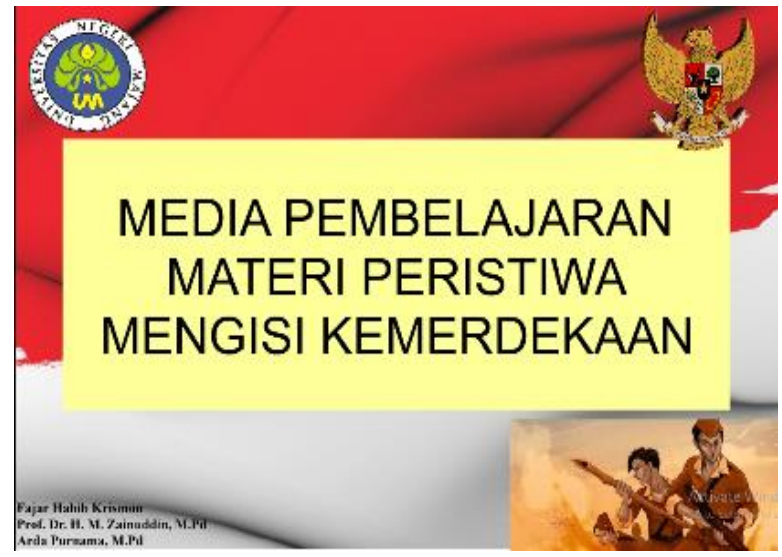

Gambar 1. Cover LKPD 


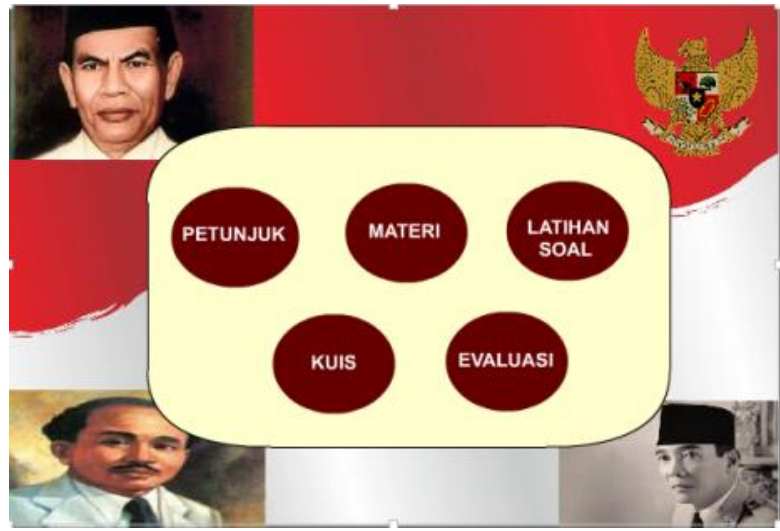

Gambar 2. Isi LKPD

Hasil validasi diperoleh melalui uji kevalidan kepada dari ahli materi dan ahli media, serta uji kerpaktisan dari pengguna. Dari hasil uji coba didapatkan data sebagai berikut.

Tabel 1. Data Hasil Validasi Ahli Materi

\begin{tabular}{|c|c|c|c|c|c|c|}
\hline No. & Indikator Penilaian & Skor & $\begin{array}{c}\text { Persentase } \\
(\%)\end{array}$ & $\begin{array}{c}\text { Nilai } \\
\text { Validasi }\end{array}$ & Kriteria & Keterangan \\
\hline 1. & Kaidah Bahasa & 4 & 100 & \multirow{4}{*}{$100 \%$} & \multirow{4}{*}{$\begin{array}{l}\text { Sangat } \\
\text { valid }\end{array}$} & \multirow{4}{*}{$\begin{array}{c}\text { Dapat } \\
\text { digunakan } \\
\text { tanpa revisi }\end{array}$} \\
\hline 2. & Kesesuaian materi & 4 & 100 & & & \\
\hline 3. & Ruang lingkup materi & 4 & 100 & & & \\
\hline 4. & Teknik penyajian & 4 & 100 & & & \\
\hline
\end{tabular}

Hasil validasi pada tabel 1 jika diinterpretasikan berdasarkan kriteria yang terdapat pada bab III, maka hasil validasi berada pada interval $85,01 \%-100,00 \%$. Artinya, produk masuk kedalam kategori sangat valid sehingga dapat digunakan tanpa revisi. Sedangkan data kualitatif yang diperoleh dari validasi ahli materi berupa saran dan masukan terhadap materi yang terdapat pada produk LKPD. Saran dan masukan dari validator ahli materi yaitu agar menunjukkan media sebelumnya yang akan dikembangkan. Saran dan masukan dari ahli materi berupa penyesuaian KKO yang digunakan dalam indikator dan tujuan. Selain itu, masukan yang diberikan adala menyesuaikan beberapa kalimat dengan bahasa yang biasa digunakan oleh anak kelas $\mathrm{V}$ agar kalimat yang ada lebih mudah untuk dipahami.

Tabel 2. Data Hasil Validasi Ahli Media

\begin{tabular}{|c|c|c|c|c|c|c|}
\hline No. & Indikator Penilaian & Skor & $\begin{array}{c}\text { Persentase } \\
(\%)\end{array}$ & $\begin{array}{c}\text { Nilai } \\
\text { Validasi }\end{array}$ & Kriteria & Keterangan \\
\hline 1. & Fisik & 4 & 100 & \multirow{3}{*}{$91 \%$} & \multirow{3}{*}{$\begin{array}{c}\text { Sangat } \\
\text { valid }\end{array}$} & \multirow{3}{*}{$\begin{array}{c}\text { Dapat } \\
\text { digunakan } \\
\text { tanpa revisi }\end{array}$} \\
\hline 2. & Tampilan & 3 & 75 & & & \\
\hline 3. & Sistematika & 4 & 100 & & & \\
\hline
\end{tabular}

Hasil validasi pada tabel 2 jika diinterpretasikan berdasarkan kriteria yang terdapat pada bab III, maka hasil validasi berada pada interval $85,01 \%-100,00 \%$. Artinya, produk masuk kedalam kategori sangat valid sehingga dapat digunakan tanpa revisi. Sedangkan data kualitatif yang diperoleh dari validasi ahli media berupa saran dan masukan terhadap produk LKPD. Saran dan 
masukan dari validator ahli media yaitu: (1) Menambahkan desain gambar ilustrasi terkait judul; (2) Huruf dibuat lebih bervariasi.

Saran dan masukan dari ahli media berupa perbaikan pada tambahan gambar ilustrasi dan huruf menjadi lebih variatif. Ahli media memberikan saran agar menambahkan gambar ilustrasi dan huruf lebih bervariasi sehingga lebih menarik dan variatif bagi siswa kelas V.

Tabel 3. Data Hasil Validasi Pengguna

\begin{tabular}{|c|c|c|c|c|c|c|}
\hline No. & Indikator Penilaian & Skor & $\begin{array}{c}\text { Persentase } \\
(\%)\end{array}$ & $\begin{array}{c}\text { Nilai } \\
\text { Validasi }\end{array}$ & Kriteria & Keterangan \\
\hline 1. & Kaidah Bahasa & 4 & 100 & \multirow{7}{*}{$100 \%$} & \multirow{7}{*}{$\begin{array}{l}\text { Sangat } \\
\text { valid }\end{array}$} & \multirow{7}{*}{$\begin{array}{c}\text { Dapat } \\
\text { digunakan } \\
\text { tanpa revisi }\end{array}$} \\
\hline 2. & Kesesuaian materi & 4 & 100 & & & \\
\hline 3. & Ruang lingkup materi & 4 & 100 & & & \\
\hline 4. & Teknik penyajian & 4 & 100 & & & \\
\hline 5. & Fisik LKPD & 4 & 100 & & & \\
\hline 6. & Tampilan LKPD & 4 & 100 & & & \\
\hline 7. & Sistematika LKPD & 4 & 100 & & & \\
\hline
\end{tabular}

Hasil validasi pada tabel 3 jika diinterpretasikan berdasarkan kriteria yang terdapat pada bab III, maka hasil validasi berada pada interval 85,01 \% - 100,00 \% . Artinya, produk masuk kedalam kategori sangat valid sehingga dapat digunakan tanpa revisi. Sedangkan data kualitatif yang diperoleh dari validasi pengguna (guru) berupa saran dan masukan terhadap produk LKPD. Komentar dari validator ahli materi yaitu LKPD cukup menarik minat peserta didik. Saran dan masukan dari pengguna, yaitu guru kelas V, LKPD ini cukup menarik minat peserta didik.

Tabel 4. Data Angket Uji Coba Lapangan

\begin{tabular}{|c|c|c|c|c|c|}
\hline No. & Deskriptor & Nilai & $\begin{array}{l}\text { Persentase } \\
(\%)\end{array}$ & $\begin{array}{c}\text { Nilai } \\
\text { Validasi }\end{array}$ & $\begin{array}{c}\text { Kriteria } \\
\text { Kepraktisan }\end{array}$ \\
\hline 1. & $\begin{array}{l}\text { Apakah kalian senang belajar peristiwa mengisi } \\
\text { kemerdekaan dengan menggunakan LKPD berbasis } \\
\text { Swishmax? }\end{array}$ & 6 & 100 & \multirow{10}{*}{$100 \%$} & \multirow{10}{*}{$\begin{array}{l}\text { Sangat } \\
\text { Praktis, tidak } \\
\text { revisi }\end{array}$} \\
\hline 2. & $\begin{array}{l}\text { Apakah LKPD berbasis Swishmax mempermudah } \\
\text { kalian dalam memahami materi peristiwa mengisi } \\
\text { kemerdekaan? }\end{array}$ & 6 & 100 & & \\
\hline 3. & $\begin{array}{l}\text { Apakah LKPD berbasis Swishmax ini menggunakan } \\
\text { Bahasa yang mudah dipahami? }\end{array}$ & 6 & 100 & & \\
\hline 4. & $\begin{array}{l}\text { Apakah petunjuk dalam LKPD berbasis Swishmax } \\
\text { sudah jelas? }\end{array}$ & 6 & 100 & & \\
\hline 5. & $\begin{array}{l}\text { Apakah pemilihan jenis huruf, ukuran, warna, dan } \\
\text { gambar menarik dan tidak mengganggu? }\end{array}$ & 6 & 100 & & \\
\hline 6. & $\begin{array}{l}\text { Apakah gambar atau ilustrasi sesuai dengan materi } \\
\text { peristiwa mengisi kemerdekaan? }\end{array}$ & 6 & 100 & & \\
\hline 7. & $\begin{array}{l}\text { Apakah soal dalam LKPD berbasis Swishmax sudah } \\
\text { sesuai? }\end{array}$ & 6 & 100 & & \\
\hline 8. & $\begin{array}{l}\text { Apakah kegiatan-kegiatan yang ada dalam LKPD } \\
\text { mempermudah memahami materi? }\end{array}$ & 6 & 100 & & \\
\hline 9. & $\begin{array}{l}\text { Apakah LKPD ini memberikan motivasi kepada } \\
\text { kalian untuk belajar? }\end{array}$ & 6 & 100 & & \\
\hline 10. & Apakah soal-soal yang disajikan mudah dipahami? & 6 & 100 & & \\
\hline
\end{tabular}

Hasil angket berdasarkan tabel 4 jika diinterpretasikan berdasarkan kriteria hasil praktis pada bab III maka masuk pada tingkat pencapaian interval $76 \leq \mathrm{P} \leq 100$ dengan kategori sangat praktis. Sehingga keputusan uji pada produk ini yaitu dapat digunakan tanpa revisi. Pada uji coba tahap 
pertama ini, karakter tanggung jawab juga terlihat ketika 4 dari 6 peserta didik mendapat nilai 4 karena memenuhi 3 indikator penilaian karakter tanggung jawab.

\section{PEMBAHASAN}

Pelaksanaan penelitian dan pengembangan ini dilaksanakan berdasarkan prosedur penelitian Dick and Carey menurut Tegeh (2014). Langkah penelitian Dick and Carey meliputi: (a) menganalisis kebutuhan untuk mengidentifikasi tujuan, (b) menganalisis pembelajaran, (c) menganalisis pembelajar dan konteksnya, (d) menuliskan tujuan unjuk kerja, (e) mengembangkan instrument penilaian, (f) mengembangkan strategi pembelajaran, (g) mengembangkan dan memilih bahan pembelajaran, (h) merancang dan melaksanakan evaluasi formatif, (i) merevisi pembelajaran, (j) merancang dan melaksanakan evaluasi sumatif.

Validasi terhadap LKPD ini dilakukan oleh ahli materi yang meliputi empat indikator yaitu kaidah Bahasa, kesesuaian materi, ruang lingkup materi dan teknik penyajian. Berdasarkan perhitungan yang telah dilakukan dari segi materi, kevalidan LKPD sebesar 100\%. Jika hasil validasi diinterpretasi berdasarkan kriteria kategorisasi yang diadopsi dari Akbar (2015) maka masuk pada tingkat pencapaian interval $85,01 \%$ - 100,00\% yang dinyatakan sangat valid, sehingga produk LKPD berbasis swishmax dengan karakter tanggung jawab dapat digunakan tanpa revisi dalam pelaksanaan pembelajaran. Hasil validasi materi ini sudah cukup baik, karena sebelumnya Umaisaroh (2016) telah mengembangkan media dengan swishmax dengan hasil validasi materi sebesar $73,8 \%$. Penyempurnaan terhadap produk LKPD ini dari ahli materi yaitu menunjukkan media sebelumnya yang akan dikembangkan dan menyesuaikan dengan kko yang digunakan dalam indikator dan tujuan.

Validasi ahli media meliputi tiga indikator yaitu fisik LKPD, tampilan LKPD, dan sitematika LKPD. Berdasarkan perhitungan yang telah dilakukan dari segi media, kevalidan LKPD sebesar 91\%. Jika hasil validasi diinterpretasi berdasarkan kriteria kategorisasi yang diadopsi dari Akbar (2015) maka masuk pada tingkat pencapaian interval $85,01 \%$ - 100,00\% yang dinyatakan sangat valid, sehingga produk LKPD berbasis swishmax dengan karakter tanggung jawab dapat digunakan tanpa revisi dalam pelaksanaan pembelajaran. Hasil validasi media ini sudah cukup baik, hal ini sejalan dengan penelitian sebelumnya oleh Pradipta (2012) telah mengembangkan media dengan swishmax dengan hasil validasi media sebesar $82,3 \%$. Media berbasis swishmax dapat membantu siswa dalam memahami materi karena terdapat gambar iilusatrasi yang menarik (Fredy, 2014; Kholifah, 2016; Saddhono, Satria, Erwinsyah, \& Abdullah, 2019) Penyempurnaan terhadap produk LKPD ini dari ahli media yaitu menambahkan desain gambar ilustrasi terkait judul dan huruf dibuat lebih bagus.

Validasi pengguna adalah guru kelas V SDN Mojoagung, adapun indikator penilaian meliputi kaidah Bahasa, kesesuaian materi, ruang lingkup materi, teknik penyajian, fisik LKPD, tampilan LKPD, dan sistematika LKPD. Berdasarkan perhitungan yang telah dilakukan dari validasi pengguna, kepraktisan LKPD sebesar $100 \%$. Jika hasil validasi diinterpretasi berdasarkan kriteria kategorisasi yang diadopsi dari Akbar (2015) maka masuk pada tingkat pencapaian interval 85,01\% - 100,00\% yang dinyatakan sangat praktis, sehingga produk LKPD berbasis swishmax dengan karakter tanggung jawab dapat digunakan tanpa revisi dalam pelaksanaan pembelajaran.

Hasil validasi pengguna ini sudah cukup baik, karena sebelumnya Sukma (2018) mengembangkan media dengan swishmax dengan hasil validasi pengguna 88,4\%. Hal ini sejalan dengan pendapat Putra et al., (2019) melalui multimedia interaktif peserta didik dapat meningkatkan daya tarik dan minat belajar, karena multimedia interaktif mengintegrasikan teks, grafik, gambar, foto, audio, video, dan animasi. Komentar yang diberikan oleh pengguna terhadap LKPD yaitu 
LKPD sudah cukup menarik minat peserta didik, ukuran tulisan dan bentuk font sudah sesuai, materi yang disajikan padat dan jelas.

\section{SIMPULAN}

Berdasarkan uji kevalidan materi, media, dan pengguna. Validasi materi yang telah dilakukan oleh ahli materi menunjukkan bahwa hasil validitas materi sebesar $100 \%$ yang masuk kategori sangat valid. Validasi media yang telah dilakukan oleh ahli media menunjukkan bahwa hasil validitas media sebesar $91 \%$ yang masuk kategori sangat valid. Validasi pengguna yang telah dilakukan oleh guru menunjukkan bahwa hasil validitas pengguna sebesar $100 \%$ yang masuk kategori sangat valid. Dari persentase data hasil validasi ahli dan pengguna, maka produk dapat digunakan tanpa revisi. Hasil angket respon siswa dari uji coba skala besar memperoleh persentase sebesar $100 \%$ yang masuk kriteria sangat praktis.

Penyebarluasan produk yang dikembangkan kepada sasaran yang luas, hendaknya memperhatikan beberapa hal, yaitu sebelum disebarluaskan sebaiknya produk dievaluasi dan disesuaikan dengan situasi dan kondisi yang dituju yaitu ketersediaan fasilitas sekolah seperti laptop, LCD, dan proyektor. Sebelum disebarluaskan sebaiknya disosialisaikan terhadap pihak-pihak terkait, seperti kepala sekolah.

\section{DAFTAR RUJUKAN}

Akbar, Sa'dun. (2015). Instrumen Perangkat Pembelajaran. Bandung: Universitas Pendidikan Indonesia.

Asmani, Jamal Ma'mur. (2009). Kompetensi Guru Menyenangkan dan Profesional.Yogyakarta: Power Books.

Fredy, B. (2014). Pengembangan Media Pembelajaran Interaktif Menggunakan Swishmax-4 pada Materi Gerak Melingkar Beraturan untuk Meningkatkan Prestasi Belajar Siswa SMA Kelas X. Jurnal Pendidikan Fisika Universitas Negeri Malang, 3.

Kholifah, S. (2016). The Development of Learning Video Media Based on Swishmax and Screencast O-Matic Software through Contextual Approach. Dinamika Pendidikan, 11(1), 50-55.

Mahanani, P., Putra, A. P., \& Kristianingsih, K. (2018). Analysis of the Influence of Understanding the Pancasila Values of Teachers on Learning in Elementary School. 1st International Conference on Early Childhood and Primary Education (ECPE 2018). 168-172. https://doi.org/https://doi.org/10.2991/ecpe-18.2018.37

Pradipta, K. R., Widjianto, M., \& Purbo Suwasono, M. S. (2012). Pengembangan Media Pembelajaran Fisika Berbasis Multimedia dengan Swishmax 4 pada Materi Kinematika Gerak Lurus untuk Siswa SMA.

Putra, A. P. et al. (2019). Interactive Multimedia Analysis in Thematic Learning: A Study of Practical Aspect. 5th International Conference on Education and Technology, ICET. https://doi.org/10.1109/ICET48172.2019.8987218

Kemdikbud. (2007). Permendiknas No. 16 tahun 2007 tentang Standar Kualifikasi Akademik dan Kompetensi Guru. Jakarta: Sekretariat Negara.

Saddhono, K., Satria, E., Erwinsyah, A., \& Abdullah, D. (2019). Designing SwiSH Max Learning Software Based of Multimedia. Journal of Physics: Conference Series, 1364(1), 12032. IOP Publishing.

Sukma, A. P., Nasution, S. P., \& Anggoro, B. S. (2018). Media Pembelajaran Matematika Berbasis Edutainment dengan Pendekatan Metaphorical Thinking dengan Swish Max. Desimal: Jurnal Matematika, 1(1), 81-89

Tegeh, I Made, dkk. (2014). Model Penelitian Pengembangan. Yogyakarta: Graha Ilmu.

Umaisaroh, U. (2016). Pengembangan Media Pembelajaran Fisika Berbasis Animasi Swishmax dengan Pendekatan Saintifik untuk Membantu Belajar Mandiri dalam Pemahaman Konsep Gerak Melingkar. SKRIPSI Jurusan Fisika-Fakultas MIPA UM. 